\title{
Magnetic Basement Depth Re-Evaluation of Naraguta and Environs North Central Nigeria, Using 3-D Euler Deconvolution
}

\author{
Opara A.I. ${ }^{1}$, Emberga T.T. ${ }^{2,}{ }^{*}$, Oparaku O.I. ${ }^{1}$, Essien A.G. ${ }^{1}$, Onyewuchi R.A. ${ }^{3}$, Echetama H.N. ${ }^{1}$, Muze N.E. ${ }^{1}$, \\ Onwe R.M $\mathbf{M}^{4}$
}

\begin{abstract}
${ }^{1}$ Department of Geosciences, Federal University of Technology, PMB 1526 Owerri
${ }^{2}$ Department of Physics and Industrial Physics, Federal Polytechnic Nekede, Owerri ${ }^{3}$ Department of Geology, University of Portharcourt, Choba, Rivers State

${ }^{4}$ Department of Gelogy/Geophysics, Federal University Ndufu-Alike Ikwo, Abakaliki *Corresponding author: terhemba4sure@yahoo.com
\end{abstract}

Received May 15, 2015; Revised July 11, 2015; Accepted July 16, 2015

\begin{abstract}
This paper presents a detailed geological interpretation of the aeromagnetic data over Naraguta and environs using 2-D spectral inversion and 3-D Euler deconvolution techniques. The objectives of the study are to reevaluate the depth to the magnetic basement and to delineate associated structural features in the study area. Data enhancement was carried out to separate residual features relative to the strong regional gradients and the more intense anomalies due to basement features and igneous intrusives. Results of the 2-D spectral analysis revealed a two layer depth source model. The deeper magnetic source bodies $\left(\mathrm{d}_{2}\right)$ varies from $1.672 \mathrm{~km}$ to $2.3 \mathrm{~km}$ with an average depth of $1.999 \mathrm{~km}$ while the depth to the shallower magnetic source bodies $\left(\mathrm{d}_{1}\right)$ ranges from $0.55 \mathrm{~km}$ to $0.897 \mathrm{~km}$ with an average depth of $0.711 \mathrm{~km}$. The shallower magnetic anomalies are believed to be as the result of basement rocks which intruded into the sedimentary rocks while the deeper layer may be attributed to magnetic basement surface and intra-basement discontinuities like faults, fractures and lineations. Structural analysis of these shallow anomalies using 3-D Euler deconvolution with structural index values ranging from 0-3, revealed three main structural models which include spheres, horizontal pipes/cylinders and sills/ dikes. Similarly, magnetic basement depth estimates using 3-D Euler deconvolution revealed a magnetic basement depth range of $0.5-2.5 \mathrm{~km}$. Finally, the average sedimentary thickness of $1.999 \mathrm{~km}$ estimated from the study area is unfavorable for hydrocarbon generation and accumulation. However, the area is more viable for solid mineral exploitation based on the presence of several intrusive and linear features which may have acted as conduits for mineralization.
\end{abstract}

Keywords: 3-D Euler deconvolution, spectral inversion, magnetic basement depth, linear features, Naraguta, Nigeria

Cite This Article: Opara A.I., Emberga T.T., Oparaku O.I., Essien A.G., Onyewuchi R.A., Echetama H.N., Muze N.E., and Onwe R.M, "Magnetic Basement Depth Re-Evaluation of Naraguta and Environs North Central Nigeria, Using 3-D Euler Deconvolution.” American Journal of Mining and Metallurgy, vol. 3, no. 2 (2015): 2942. doi: 10.12691/ajmm-3-2-1.

\section{Introduction}

The importance of airborne survey in the delineation of structural discontinuities within sedimentary basins and the underlying basement has been tremendous over the past few decades. This past decade has seen a departure from the usual interpretation of basement structures only to detailed studies with respect to both lithologic and morphologic variations [6]. Basement structures and depths can be accurately delineated and mapped using magnetic data. Definition of various basin and sub-basin geometries can enable the mapping of the regional hydrocarbon and mineral fetch areas. Trends in magnetic features often have related trend in the overlying sediments: systematic offset of magnetic anomalies may indicate strike-slip faults which may have displaced basement rocks and possibly affect the sediment section. Infact magnetic basement interpretation can to a certain extent lead to a better understanding of the structures of the overlying sedimentary rocks.

A typical contoured aeromagnetic map presents several anomalies whose sources are traceable to the basement. It now becomes imperative that depth estimation from those anomalies provide useful clues to approximate estimation of sedimentary thickness. Aeromagnetic survey data are routinely interpreted by estimating source depths or locations; consequently, many processing algorithms have been proposed to assist the estimation [14]. The application of 2-D spectral inversion to the interpretation of potential field data is one method that has been used to determine the basement depth, and is now sufficiently well established [18]. Several authors have applied 
spectral inversion techniques in the determination of sedimentary thickness in various basins of the world $[8,10,12,13,15,22]$ The magnetic anomaly signature characteristics are results of one or more physical parameters such as the configuration of the anomalous zone, magnetic susceptibility contrasts, as well as the depth to the anomalous body. Similarly, airborne magnetic survey data in grid form may be interpreted rapidly for source positions and depths by deconvolution using Euler's homogeneity relationships [14]. The method employs gradients, either measured or calculated with the details of this method sufficiently discussed by previous scholars [14]. A robust magnetic data set is likely to contain anomalies from sources with various structural indices. It is, therefore, necessary to solve for a range of indices (say 0.0, 0.5, and 1.0) and to plot the results for each index. The maps are then examined feature by feature and the index which gives the best solution clustering is chosen for each feature. This procedure which was adopted for this study also gives some clue as to the nature of the feature. Thus, a sill edge, dike, or fault with limited throw is best displayed at an index of 1.0, while a fault with large throw may be best displayed at a zero index. Intermediate cases are best shown by an index of 0.5 [14]. However, it should be noted that field data need not be pole-reduced, so that remanence is not an interfering factor. Geologic constraints are imposed by the use of a structural index with the method known to locate or outline confined sources, vertical pipes, dikes, and contacts with remarkable accuracy [14].

This study, therefore attempts to estimate depth to anomalous magnetic sources within the study area using 2-D spectral analysis and 3-D Euler deconvolution techniques. Structural interpretation was also carried out on the contoured aeromagnetic data with a view of locating structures that may possibly accommodate minerals.

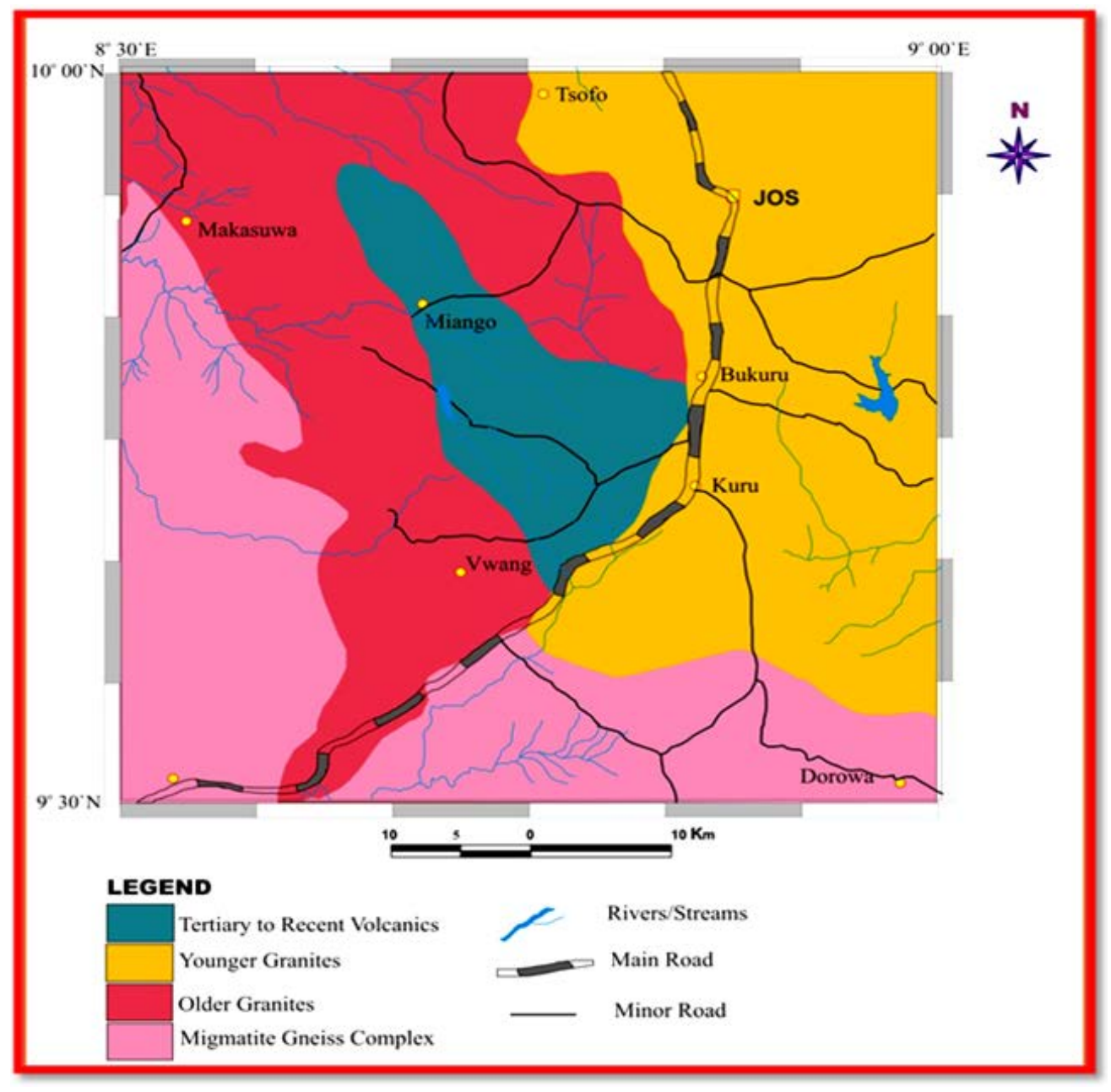

Figure 1. Geological map of Naraguta and environs

\subsection{Background Geology}

The area studied is Naraguta and environs which is located within the Jos-Bukuru Younger Granite Ring Complex of North Central Nigeria in the mining district of Jos. It is located at about latitudes $9^{\circ} 30^{1}-10^{\circ} 00^{1} \mathrm{~N}$ and longitudes $8^{\circ} 30^{1}-9^{\circ} 00^{1} \mathrm{E}$ (Figure 1). The Nigerian Younger Granite Ring complexes are a series of petrologically distinctive crystalline igneous rocks of granitic composition [11]. Several individual complexes have been identified with varying sizes and named after their localities with individual massifs ranging from $640 \mathrm{~km}^{2}$ to less than $1.68 \mathrm{~km}^{2}$ [11]. The Younger Granites are believed to be discordant high level intrusions emplaced by means of piecemeal stopping through the collapsed central block [11]. Their outlines are either circular or elliptical. Several cycles of intrusions occur within one complex. The sizes of many of the structures are due to overlapping and superposition of separate intrusive cycles $[2,4,17,19]$. The Younger Granites were 
preceded by extensive acid volcanism and emplaced by ring faulting and block subsidence. Granites and rhyolites underlay more than 90 percent of the total area of the Younger Granite province. Intermediate and basic rocks occur in many complexes. Their emplacement is completely unrelated to orogenic activity associated with the study area $[2,20]$. Their age is Jurassic, around 160 to 170 million years; the Older Granites and the accompanying metamorphism of the basement are dated at about 500 to 600 million years, and represent the Pan African Orogeny in Nigeria [2,4]. However, it seem likely that emplacement of the Younger Granites was associated with epeirogenic uplift [20]. Indirect evidence for this is lack of sediments associated with the volcanic rocks of the younger granite age, which are apparently erupted on to a land surface undergoing erosion, not deposition [20]. The major components of most complexes are granitic ring dykes that range from $5 \mathrm{~km}$ or less to over $30 \mathrm{~km}$ in diameter.

Generally, the Younger Granites are characterized as anorogenic, peralkaline rocks that intruded the basement discordantly to form highly steeped hills. They occur generally as ring dykes and cone sheets. The province contains approximately 50 Jurassic Ring Complexes (165MA), which intruded into the Precambrian basement complex (600MA) within the Central Plateau Region of the Jos Plateau of Nigeria [9]. The geology map (Figure 1) of the study area revealed that the area is underlain by the Precambrian crystalline basement of migmatite-gneiss complex which is directly overlain by the older granites, subsequently by younger granites and then the newer basalts of quaternary-tertiary age that occurs as lava flows and volcanic cone.

\section{Theory and Method}

The data used in this study are part of the airborne aeromagnetic map project of Nigeria obtained from the Geological Survey Agency of Nigeria and was subjected to low pass filtering operation. The generated filtered total field magnetic intensity values are presented in Figure 2 as a contour map. The nature of filtering applied in this study in the fourier domain was chosen to eliminate certain wavelengths and to pass longer wavelengths. Regional residual separation was also carried out using polynomial fitting. This is a purely analytical method in which matching of the regional by a polynomial surface of low order exposes the residual features as random errors. For the magnetic data, the regional gradients were removed by fitting a plane surface to the data by using multiregression least squares analysis. The expression obtained for the regional field $T(R)$ is given as:

$$
\mathrm{T}(\mathrm{R})=7612.158+0.371 \mathrm{x}-0.248 \mathrm{y}
$$

Furthermore, estimation of the source depths for the various anomaly depths were carried out using slope methods which includes Peter's, Half width and Thannel's analytical rules. The original aeromagnetic field maps over the study area are characterized by a series of local anomalies which are not apparent on the residual maps due to the digital filtering and convolution algorithm used. These local anomalies were modeled in terms of intrusions which are known to occur in the area using non linear optimization techniques. In summary, the method seek to minimize a non linear objective function which represents the difference between the observed and calculated fields through an iterative change of the non linear parameters (location, thickness and depth) by non-linear optimization while at the same time obtaining optimum values for the linear parameters (magnetization components, quadratic regional and composite magnetization angle) by leastsquare analysis [12]. Many of these prominent local anomalies are associated with intrusive igneous bodies and mineral veins found in the area. Detailed Interpretations of these anomalies in the study area are also presented in this study in Table 2.

In addition, 2-D spectral analysis which allows an estimate of the depth of an ensemble of magnetized blocks of varying depth, width, thickness and magnetization was also carried out in this study. The digitized aeromagnetic data was transformed in the fourier domain to compute the energy (or amplitude) spectrum. This was then plotted on a logarithmic scale against frequency. The slopes of the segments yielded estimates of average depths to magnetic sources of anomalies in the study area $[7,12,18]$. Given a residual magnetic anomaly map of dimensions $\mathrm{l} \times \mathrm{l}$, digitized at equal intervals, the residual total intensity anomaly values can be expressed in terms of a double fourier series expression given as $[7,18]$ :

$$
\mathrm{T}(x, y)=\sum_{n=1}^{N} \sum_{n=1}^{N}\left\{\begin{array}{l}
P_{m}^{n} \cos \left\{\left(\frac{2 \pi}{l}\right)(n x+m y)\right\} \\
+Q_{m}^{n} \sin \left\{\left(\frac{2 \pi}{l}\right)(n x-m y)\right\}
\end{array}\right\}
$$

where, 1 = dimensions of the block, and is the Fourier amplitude and $\mathrm{N}$ and $\mathrm{M}$ are the number of grid points along the $\mathrm{x}$ and $\mathrm{y}$ directions respectively. Similarly, using the complex form, the two dimensional Fourier transform pair may be written as $[7,18]$ :

$$
G(u, v)=\iint_{-\infty}^{\infty} g(x, y) e^{-j\left(u_{x}+v_{y}\right)} d x d y
$$

and

$$
g(x, y)=\iint_{-\infty}^{\infty} G(u, v) e^{-j\left(u_{x}+v_{y}\right)} d u d v
$$

where, $\mathrm{u}$ and $\mathrm{v}$ are the angular frequencies in the $\mathrm{x}$ and $\mathrm{y}$ directions respectively.

The use of this method involves some practical problems, most of which are inherent in the application of the discrete fourier transform (DFT). They include the problems of aliasing, truncation effect or Gibb's phenomenon, and the problems associated with even and odd symmetries of the real and imaginary parts of the fourier transform [12]. However, in this study, these problems were taken care of by the softwares used in the analysis.

Finally, the objective of the 3-D Euler deconvolution process was to produce maps showing the locations and the corresponding depth estimates of geologic sources of magnetic anomalies in a two-dimensional grid [14,23]. The Standard 3-D Euler method is based on Euler's homogeneity equation, which relates the potential Field (magnetic) and its gradient components to the location of the sources, by the degree of homogeneity $\mathrm{N}$, which can 
be interpreted as a structural index $[19,23]$. The method makes use of a structural index in addition to producing depth estimates. In combination, the structural index and the depth estimates have the potentials to identify and calculate depth estimates for a variety of geologic structures such as faults, magnetic contacts, dykes, sills, etc. The algorithm uses a least squares method to solve Euler's equation simultaneously for each grid position within a sub-grid (window). A square window of predefined dimensions (number of grid cells) is moved over the grid along each row. At each grid point, a system of equations is solved from which the four unknowns ( $\mathrm{x}, \mathrm{y}$ as location in the grid, $\mathrm{z}$ as depth estimation and the background value) and their uncertainties (standard deviation) are obtained for a given structural index. A solution is only recorded if the depth uncertainty of the calculated depth estimate is less than a specified threshold and the location of the solution is within a limiting distance from the center of the data window [14,23]. Thompson [19] showed that for any homogenous, threedimensional function $\mathrm{f}(\mathrm{x} ; \mathrm{y} ; \mathrm{z})$ of degree $\mathrm{n}$ :

$$
\mathrm{f}(\mathrm{t} x ; \mathrm{t} y ; \mathrm{tz})=\mathrm{t}^{\mathrm{n}} \mathrm{f}(\mathrm{x} ; \mathrm{y} ; \mathrm{z})
$$

It can be shown that, the following equation, which is known as Euler's homogeneity relation can be satisfied [23]:

$$
x \frac{\delta f}{\delta x}=y \frac{\delta f}{\delta y}+z \frac{\delta f}{\delta z}=n f
$$

In geophysics, the function $\mathrm{f}(\mathrm{x}, \mathrm{y}, \mathrm{z})$ can have the general functional form [14,19,23]:

$$
f(x . y, z)=\frac{G}{r^{N}}
$$

Where $\mathrm{r}^{2}=\left(\mathrm{x}-\mathrm{x}_{0}\right)^{2}+\left(\mathrm{y}-\mathrm{y}_{0}\right)^{2}+\left(\mathrm{z}-\mathrm{z}_{0}\right)^{2}, \mathrm{~N}$ is a real number $(1,2,3 \ldots)$ and $\mathrm{G}$ a constant (independent of $\mathrm{x}, \mathrm{y}, \mathrm{z}$ ). Many simple point magnetic sources can be described by equation 7 above, with $\left(\mathrm{x}_{0} ; \mathrm{y}_{0} ; \mathrm{z}_{0}\right)$ the position of the source whose field $\mathrm{F}$ is measured. The parameter $\mathrm{N}$ is dependent on the source geometry, a measure of the falloff rate of the field and may be interpreted as the structural index (SI). Considering potential field data, Euler's equation can be written as $[19,23]$ :

$$
\left(x-x_{0}\right) \frac{\delta T}{\delta x}+\left(y-y_{0}\right) \frac{\delta T}{\delta y}+\left(z-z_{0}\right) \frac{\delta T}{\delta z}=N(B-T)
$$

With $\mathrm{B}$ the regional value of the total magnetic field and $\left(\mathrm{x}_{0} ; \mathrm{y}_{0} ; \mathrm{z}_{0}\right)$ the position of the magnetic source, which produces the total field $\mathrm{T}$ measured at $(\mathrm{x} ; \mathrm{y} ; \mathrm{z})$.

Thompson [19] showed that simple magnetic models are consistent with Euler's homogeneity equation. Thus Euler deconvolution provides an excellent tool for providing good depth estimations and locations of various sources in a given area, assuming that appropriate parameter selections are made. Applied to aeromagnetic surveys, the 3-D Euler process is a fast method for obtaining depth and boundary solutions of magnetic sources for large areas. Though it is a general advantage of the Euler deconvolution method, that it is applicable to all geologic models and that it is insensitive to magnetic remanence and geomagnetic inclination and declination, an initial assumption of the source type has to be made.
Dependent upon the potential source type, a structural index is chosen. Table 1 summarizes the structural indices (SI) for given geologic models. The number of infinite dimensions describes the extension of the geologic model in space.

Table 1. Structural Indices for Simple Magnetic Models Used For Depth Estimations by 3-D Euler Deconvolution [14,19,23]

\begin{tabular}{|c|c|c|}
\hline Geologic Model & $\begin{array}{c}\text { Number of Infinite } \\
\text { Dimensions }\end{array}$ & $\begin{array}{c}\text { Magnetic } \\
\text { Structural Index }\end{array}$ \\
\hline Sphere & 0 & 3 \\
\hline Pipe & $1(\mathrm{z})$ & 2 \\
\hline Horizontal cylinder & $1(\mathrm{x}-\mathrm{y})$ & 2 \\
\hline dyke & $2(\mathrm{z}$ and $\mathrm{x}-\mathrm{y})$ & 1 \\
\hline sill & $2(\mathrm{x}$ and $\mathrm{y})$ & 1 \\
\hline contact & $3(\mathrm{x}, \mathrm{y}, \mathrm{z})$ & 0 \\
\hline
\end{tabular}

The results of the Euler method are displayed in ordinary maps as point solutions combining the location (position of solution) and the depth (colour range). Given the choice of an appropriate structural index, 3-D Euler deconvolution will lead to a clustering of solutions, which can be interpreted. A vertical pipe structure will for example be shown as a cluster of solutions around a specific point, whereas an elongated dyke structure will be recognized as a linear trend of solutions.

\section{Results and Interpretation}

The aeromagnetic data used in this work was obtained from the Geological Survey Agency of Nigeria. It was part of the nationwide survey completed in 1976 by Fairey Survey Ltd. Flight line direction was NNW-SSE at station spacing of $2 \mathrm{~km}$ with flight line spacing of $20 \mathrm{~km}$.It was flown at an altitude of about $150 \mathrm{~m}$ with tie lines in an ENE-WSN direction. Regional correction of the magnetic data was based on the IGRF (epoch date1 of January, 1974). For this study, aeromagnetic sheet 168 (Naraguta sheet) was used.

The total magnetic field intensity map derived from the digitization is presented as a total field intensity map and 3-D map respectively (Figure 2 \& Figure 3 ). The total field of the aeromagnetic data revealed that the underlying basement within Bukuru, Kuru and Jos have an estimated magnetic intensity range of 7740 to 7780 gammas. This area has a broad relief with low intensity surrounded by fairly high to high intensity area which may be interpreted as trough. The 3-D map revealed two distinctive relief patterns: low and high relief. Areas with low relief are observed in the central part of the study area: Bukuru, Kuru and Jos whereas, the northern and southern fringes of the study area around Tsofo and Makasuwa showed a relatively high relief (Figure 3). On the northern fringe, from Tsofo, an extensive linear anomaly trending in the EW direction was observed. Along this linear anomaly, there exists a chain of circular magnetic closures suspected to be granitic intrusions which is believed to be part of the volcanic ring complex. The high relief areas are also believed to be more tectonically active than the low relief area owing to the presence of chains of granitic intrusive surfaces present in the area. Another linear anomaly was observed in the southeastern portion of the study area. This anomaly with a sharp gradient was believed to be a linear feature of regional extent. Other 
magnetic closures suspected to be intrusions were observed around Makasuwa and environs.

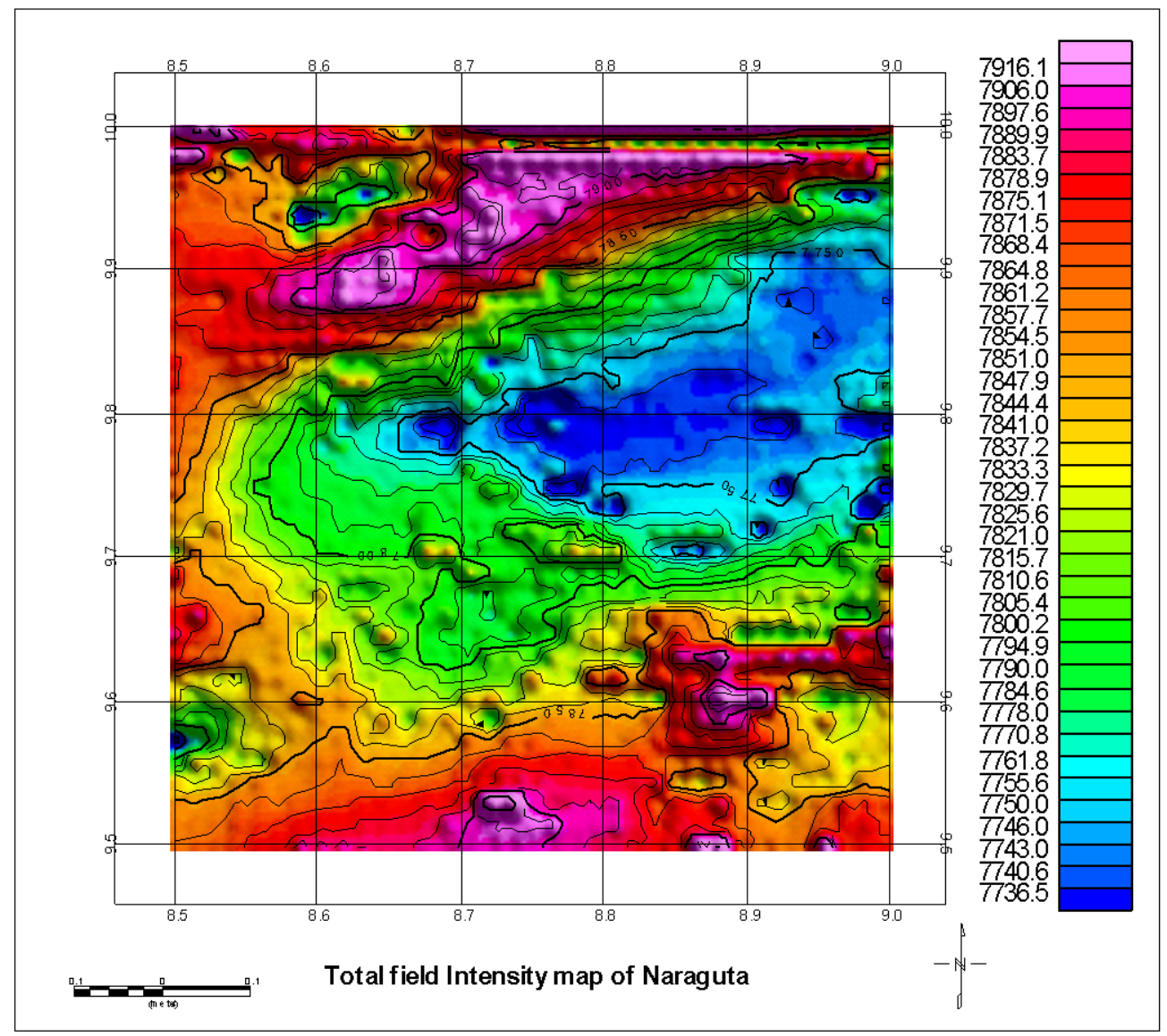

Figure 2. Total Magnetic Field Intensity Contour Map of the Study area

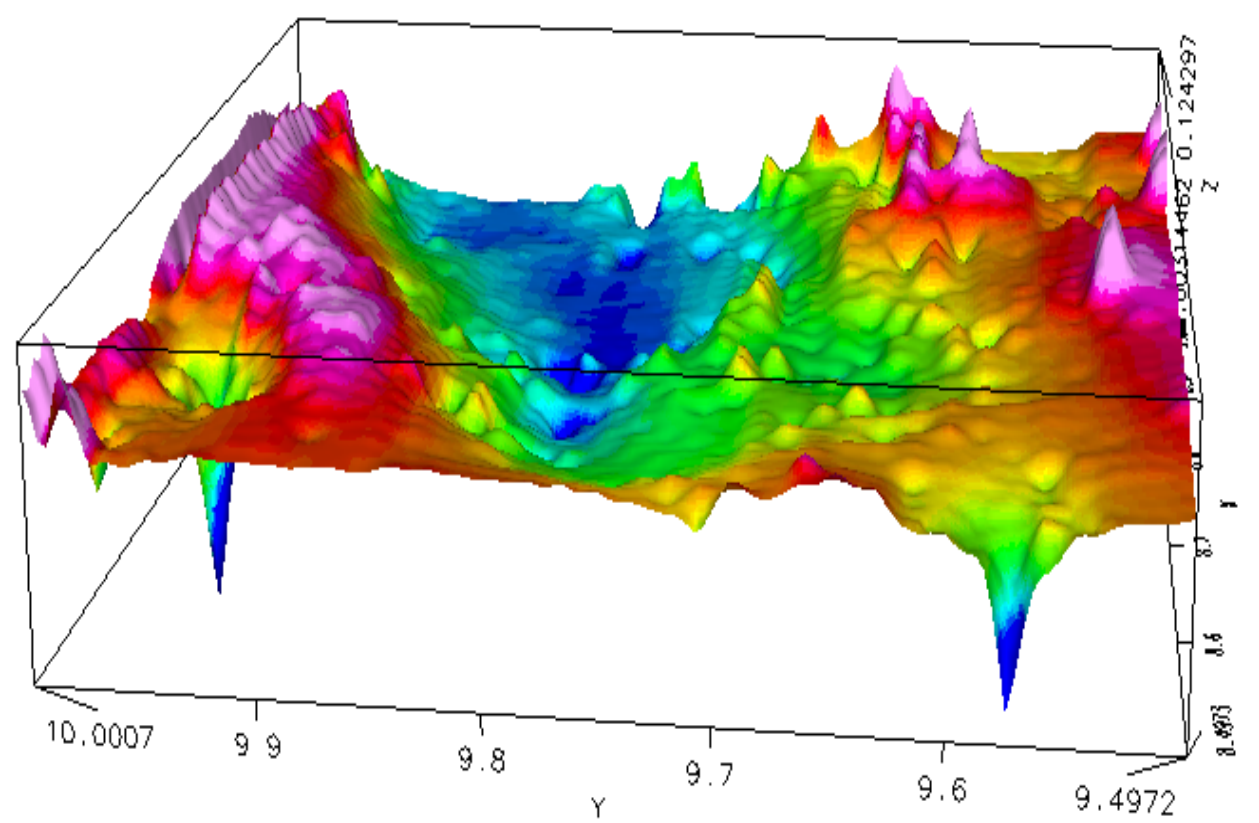

Figure 3. 3-D Surface map of the magnetic basement surface of the study area

The Structural trends interpreted from the total field intensity map, polynomial surfaces (Figure 4) and the residual field map (Figure 5) reveled trend directions of NW-SE,N-S, E-W and NE-SW. The NW-SE trend is the dominant trend orientation in the study area and thus reflects the trend of the youngest tectonic episode, the Post pan African orogenic activities in the study area which nearly obliterated the older E-W and NE-SW tectonic trends of Pan African orogenic phase. The regional fields established the major tectonic elements of the deeper and regional field which affected the structural framework of the study area. These structural trends are correlatable with paleo-structures in the study area which are believed to have affected major geologic events in the study area. Buser [5] suggested the existence of these paleo-structures within the study area and its surroundings. 

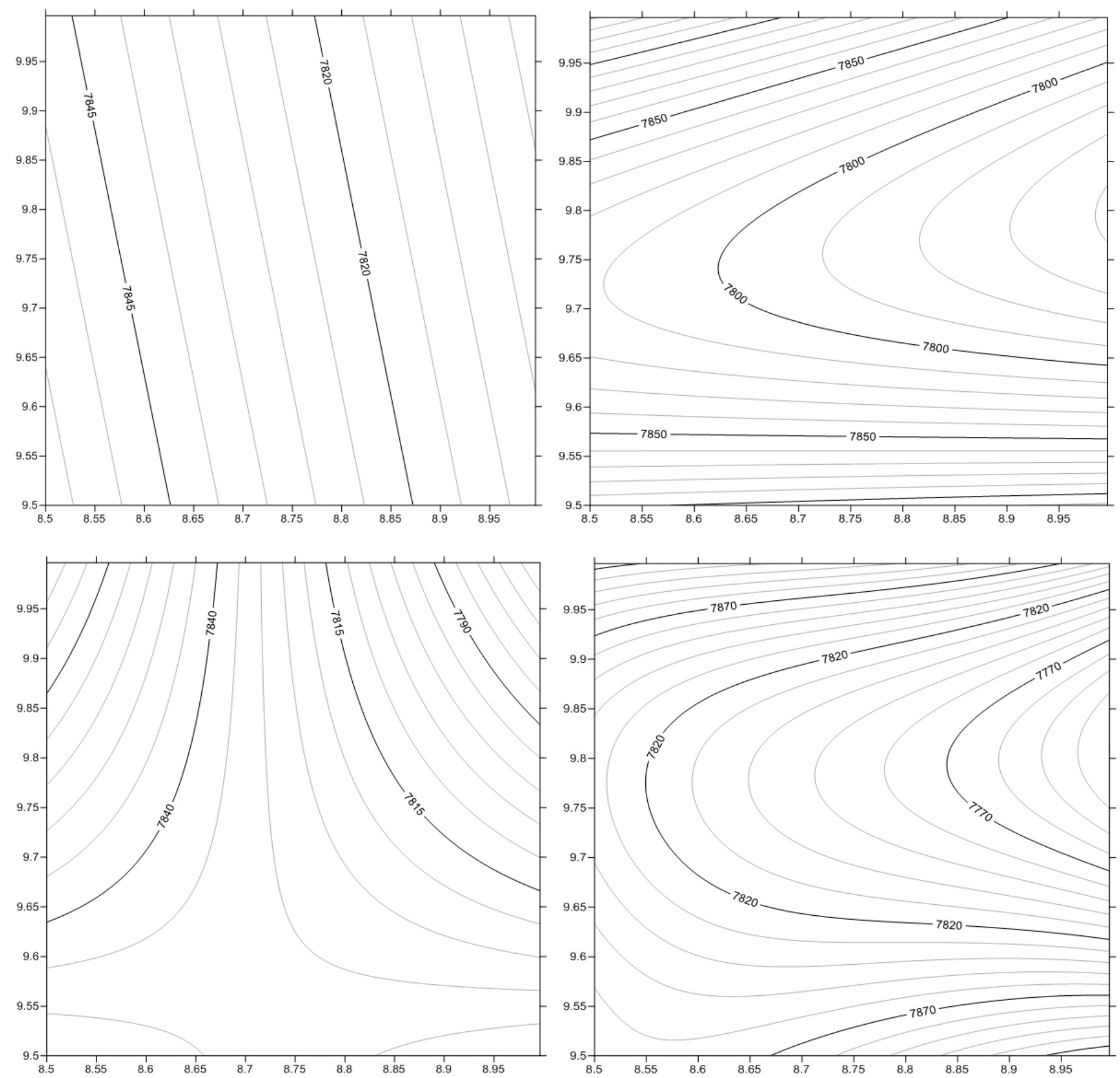

Figure 4. First to fourth degree(polynomial) surfaces of the regional fields of the aeromagnetic data

The residual magnetic intensity values (Figure 5) of the study area was discovered to range from -89.9 to 91.9 gammas. The extensive linear feature earlier interpreted from the total field intensity map around Tsofo has a positive residual value of 80 gammas. Other areas with positive residual values are Makasuwa on the central portion and Dorowa on the southern extreme of the study area. Similarly, Bukuru and Kuru on the central portion of the study area was observed to be dominated by low residual magnetic intensity. The residual intensity range in these areas was shown to be between -89.9 to -85.2 . The areas with negative magnetic values reflects a typical zone of low magnetization while the positive residual anomalous areas are indicative of an area of high magnetization. This implies that there is an existence of shallow to near surface magnetized bodies in areas having positive residual values. It also indicated that the linear anomalous body seen at Tsofo could be interpreted as a near surface magnetized body. It further implies that Bukuru and Kuru with negative residual values is underlain by deep seated magnetized bodies. Another probable reason for the predominance of negative residual anomaly signatures in this area may be due to its nearness to the magnetic equator. Apart from the linear anomalies, there are circular closures seen on the extreme northwestern and southern portions of the map. These circular anomaly patterns were interpreted as the Younger Granite Ring Complexes which are believed to be associated with the presence of ore bodies; granitic as well as basic ore bodies.

The local anomalies in the original aeromagnetic field map were modeled in terms of intrusions using non linear optimization techniques. The method seek to minimize a non linear objective function which represents the difference between the observed and calculated fields through an iterative change of the non linear parameters (location, thickness and depth) by non-linear optimization while at the same time obtaining optimum values for the linear parameters (magnetization components, quadratic regional and composite magnetization angle) by least- 
square analysis. The analytical slope methods mainly Peter's, slope, Thannel and Half-width graphical methods were also used in calculating depth estimates to the anomalous bodies (Figure 6). The estimated depths and linear parameters are presented in Table 2 and Figure 6. The depth to the anomalous magnetic features from the three depth slope methods varies from $0.1601 \mathrm{~km}$ to $2.478 \mathrm{~km}$.
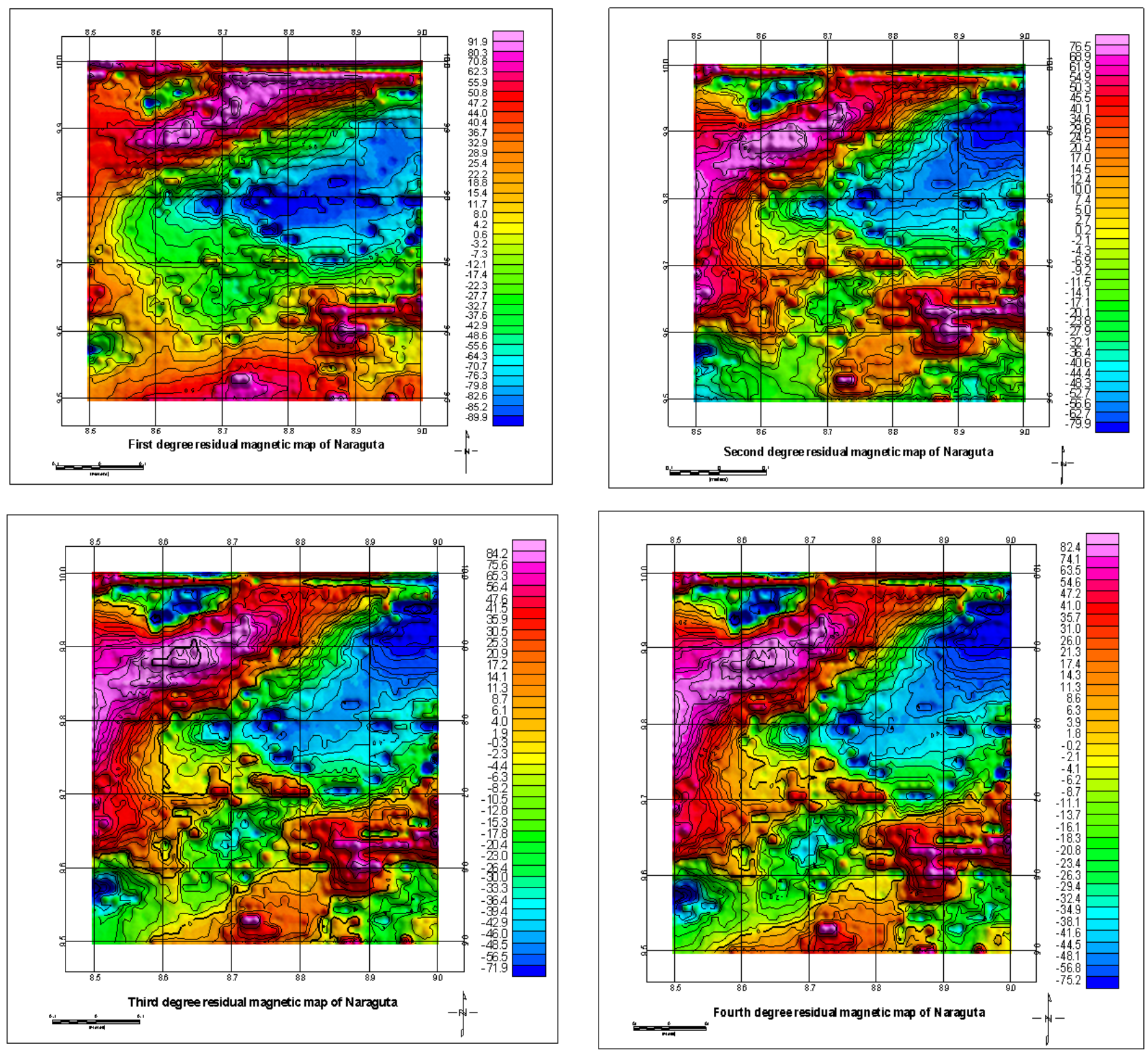

Figure 5. First to fourth degree residual fields of the aeromagnetic data of the study area

Table 2. Calculated Depth to the Magnetic Source of the aeromagnetic map of Naraguta Area

\begin{tabular}{|c|c|c|c|c|c|c|c|c|c|}
\hline $\begin{array}{c}\text { SHEET } \\
168\end{array}$ & LOCATION & \multicolumn{2}{|c|}{ DEPTH ESTIMATION } & $\begin{array}{c}\text { WIDTH } \\
\text { INM KM }\end{array}$ & $\begin{array}{c}\text { AMPLITUDE } \\
\text { IN GAMMA }\end{array}$ & $\begin{array}{c}\text { MAGNETIZATION } \\
\text { (A/M) }\end{array}$ & $\begin{array}{c}\text { 1\% } \\
\text { RADIANCE }\end{array}$ & $\begin{array}{c}\text { TYPE OF } \\
\text { ANOMALY }\end{array}$ \\
\hline PROFILE & TOWNS & $\begin{array}{c}\text { PETER'S } \\
\text { SLOPE }\end{array}$ & $\begin{array}{c}\text { THANNEL'S } \\
\text { RULE }\end{array}$ & $\begin{array}{c}\text { HALF } \\
\text { WIDTH } \\
\text { RULE }\end{array}$ & & & & & \\
\hline $\mathrm{AA}^{1}$ & $\begin{array}{c}7 \mathrm{~km} \text { NW of } \\
\text { Manchox }\end{array}$ & 0.4726 & 1.5976 & 0.8476 & 4.02 & 7808 & 0.90 & -1.15 & LOW \\
\hline $\mathrm{BB}^{1}$ & $\begin{array}{c}\text { 9km East of } \\
\text { Barkin } \\
\text { Darowa }\end{array}$ & 1.0976 & 1.5976 & 1.8476 & 8.0 & 7900 & 0.55 & 1.38 & HIGH \\
\hline $\mathrm{CC}^{1}$ & $\begin{array}{c}7.5 \mathrm{~km} \text { North } \\
\text { of } \\
\text { Damakasuwa }\end{array}$ & 0.1601 & 1.6476 & 0.5476 & 3.75 & 7645 & 1.65 & 1.46 & LOW \\
\hline $\mathrm{DD}^{1}$ & $\begin{array}{c}\text { 8km NW of } \\
\text { Bukuru }\end{array}$ & 0.1601 & 2.6476 & 1.6476 & 4.6 & 7650 & 1.85 & 1.23 & LOW \\
\hline $\mathrm{EE}^{1}$ & $\begin{array}{c}7 \mathrm{~km} \text { NE of } \\
\text { Miango }\end{array}$ & 0.7876 & 2.2976 & 0.3476 & 6.2 & 7859 & 2.09 & 1.75 & LOW \\
\hline $\mathrm{FF}^{1}$ & $\begin{array}{c}1 \mathrm{~km} \text { West of } \\
\text { JOS }\end{array}$ & 0.3476 & 1.2476 & 0.4476 & 4.0 & 7854 & 1.52 & 1.83 & HIGH \\
\hline
\end{tabular}




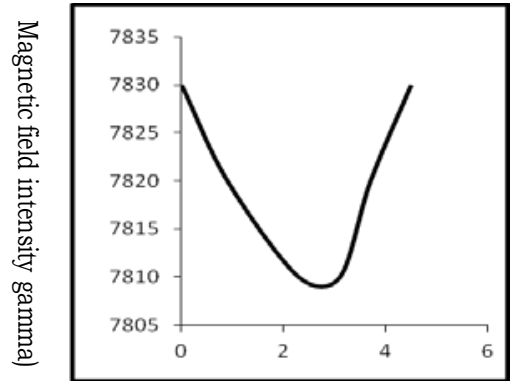

distance $(\mathrm{km})$
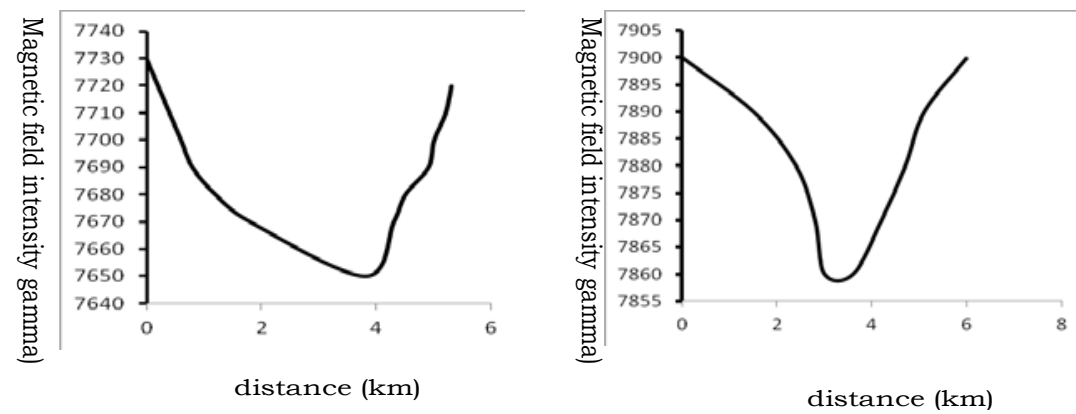

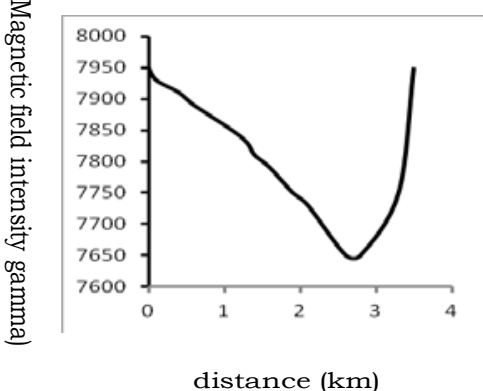

distance $(\mathrm{km})$

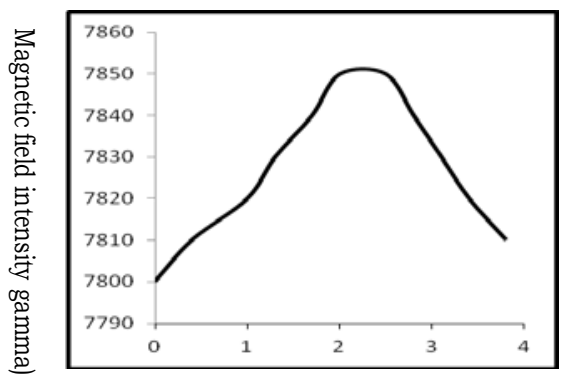

distance $(\mathrm{km})$

Figure 6. Interpretation of some linear magnetic anomalies from Naraguta Sheet. Profiles A $\rightarrow$ F were taken as follows: Profile[A], 7Km NW of Manchox; Profile[B], 9Km East of Barkin Dorowa; Profile[C], 7.5Km North of Damakasuwa; Profile [D], 8Km NW of Bukuru; Profile [E], 7Km NE of Miango; Profile [F], 1Km West of Jos

Similarly, the second vertical derivative contour map of the study area is presented in Figure 7a below. The zero contours of the second vertical derivative map indicated the lithologic boundaries between the the different lithologies (Figure 7a). A good correlation was also established between the second vertical derivative map and the mineral map of the study area as shown in Figure 7b. In addition, the distribution of mafic and felsic rock forming minerals were correlated to the positive and negative second vertical derivative anomalies around the study area close to Ifinkpa, Agoi Ibani and Iko Ikperem areas (Figure 7a). The mafic and felsic rock minerals are believed to be the by-product of the re-activation of the trans-oceanic fracture zones that also acted as conduits for primary mineralization. In the study area around Ifinkpa, Agoi.

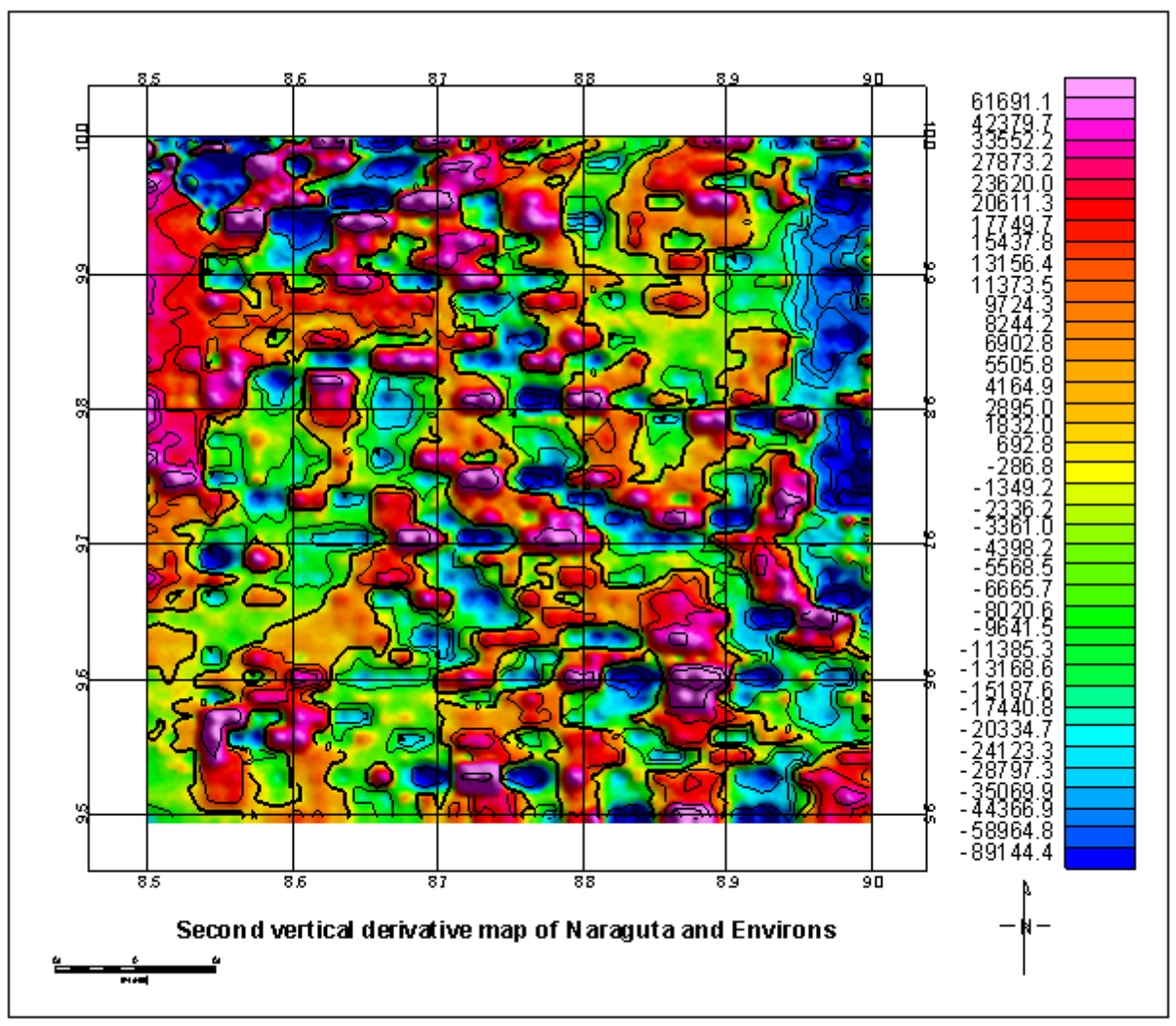

Figure 7a. Contour map of Second vertical derivatives of the aeromagnetic map of the study area 

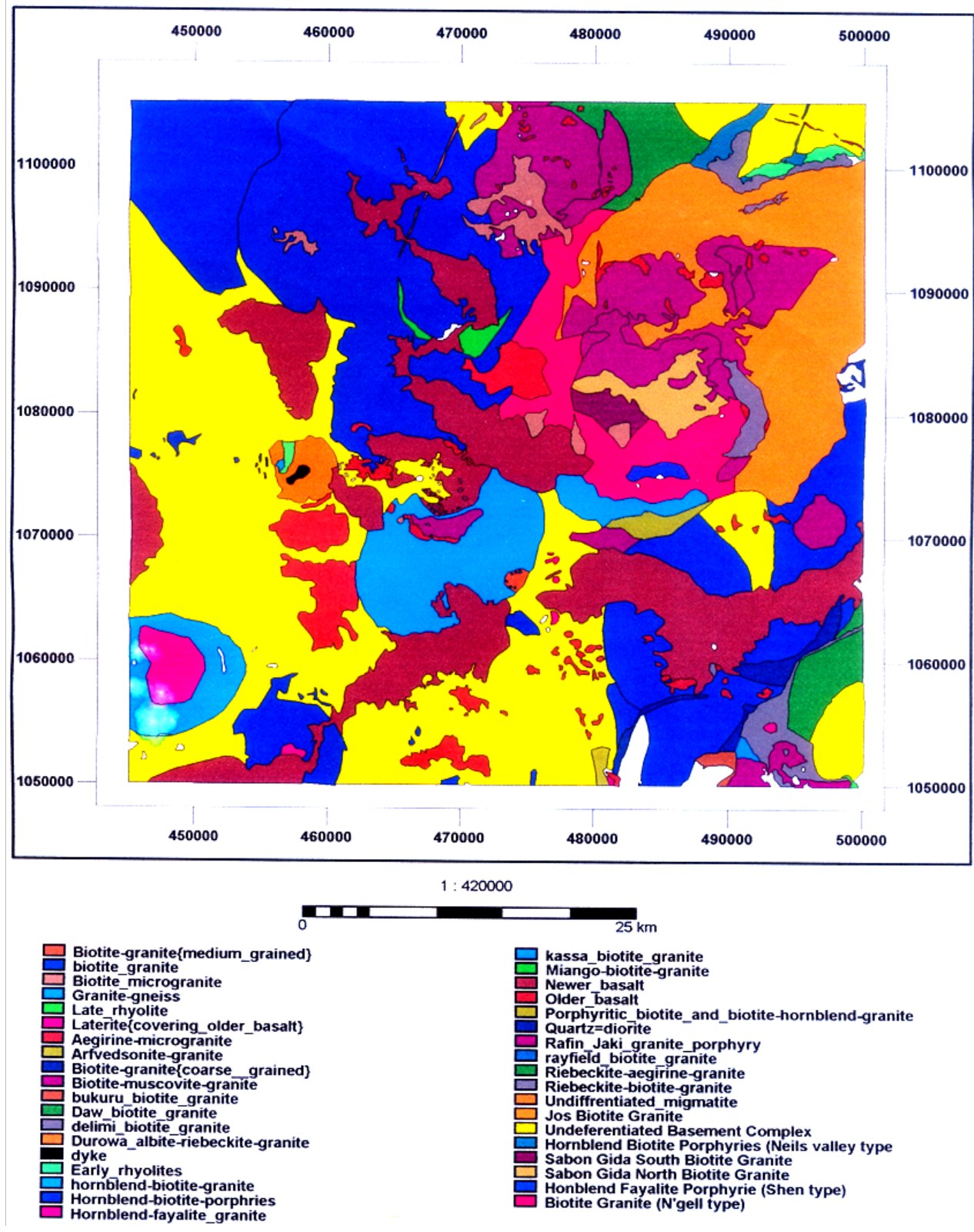

Figure 7b. Geology map of the study area showing mineral distribution (NGSA)

The spectral analysis plot of the power spectrum of the residual field of the study area was used to estimate the average depth to buried magnetic rocks and is presented as Figure 8 below. The spectral analysis presents a two layer $\left(D_{1}\right.$ and $\left.D_{2}\right)$ depth source model. These depths were established from the slope of the log- power spectrum at the lower end of the total wave number or spatial frequency band. The method allows an estimate of the depth of an ensemble of magnetized blocks of varying depth, width, thickness and magnetization. The estimated depths to magnetic basement are shown as $D_{1}$ and $D_{2}$ (Table 3).

Table 3. Location and magnitude of first and second layer spectral depths

\begin{tabular}{|c|c|c|c|c|c|c|}
\hline SPECTRAL BLOCK & \multicolumn{2}{|c|}{ LONGITUEE } & \multicolumn{2}{c|}{ LATITUDE } & \multicolumn{3}{c|}{ DEPTH (KM) } \\
\hline & $\mathrm{X}_{1}$ & $\mathrm{X}_{2}$ & $\mathrm{Y}_{1}$ & $\mathrm{Y}_{2}$ & $\mathrm{D}_{1}$ & $\mathrm{D}_{2}$ \\
\hline $\mathrm{A}$ & 8.5 & 8.75 & 9.75 & 10 & 0.55 & 1.672 \\
\hline $\mathrm{B}$ & 8.75 & 9 & 9.75 & 10 & 0.63 & 2.3 \\
\hline $\mathrm{C}$ & 8.5 & 8.75 & 9.5 & 9.75 & 0.765 & 1.863 \\
\hline $\mathrm{D}$ & 8.75 & 9 & 9.5 & 9.75 & 0.897 & 2.161 \\
\hline
\end{tabular}

The first layer depth $\left(\mathrm{D}_{1}\right)$, is the depth to the shallower source represented by the second segment of the spectrum (Figure 8 ). This layer $\left(\mathrm{D}_{1}\right)$ varies from $0.55 \mathrm{~km}$ to $0.897 \mathrm{~km}$, with an average of $0.711 \mathrm{~km}$. The second layer depth $\left(\mathrm{D}_{2}\right)$ varies from $1.672 \mathrm{~km}$ to $2.3 \mathrm{~km}$, with an average of $1.999 \mathrm{~km}$ (Table 3). This layer may be attributed to magnetized rocks of the basement surface. Another probable origin of the magnetic anomalies contributing to this layer are the lateral variations in basement susceptibilities, and intra-basement features like faults and fractures $[8,12]$. It can be deduced from the spectral plots that the $D_{2}$ values obtained from the spectral plots represent the average depths to the basement complex in the blocks considered. The depth of the shallower magnetic source and that of the magnetic basement increases from west to east (Figure 9). This revealed that 
the basement outcropped around Makasuwa suggesting epirogenic uplift. Similarly, the sediment thickness is
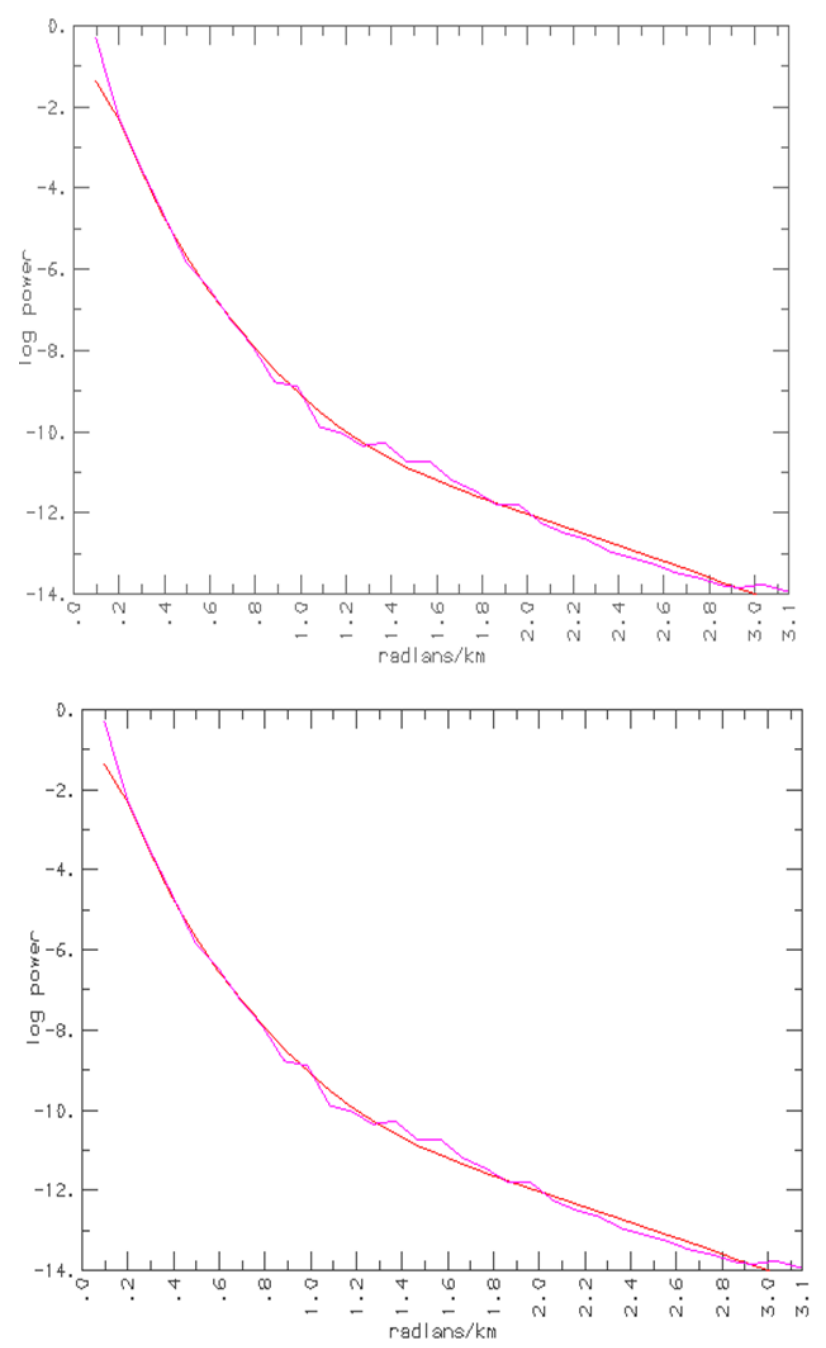

believed to be more within Kuru, Bukuru and Jos areas indicating a thicker overburden.
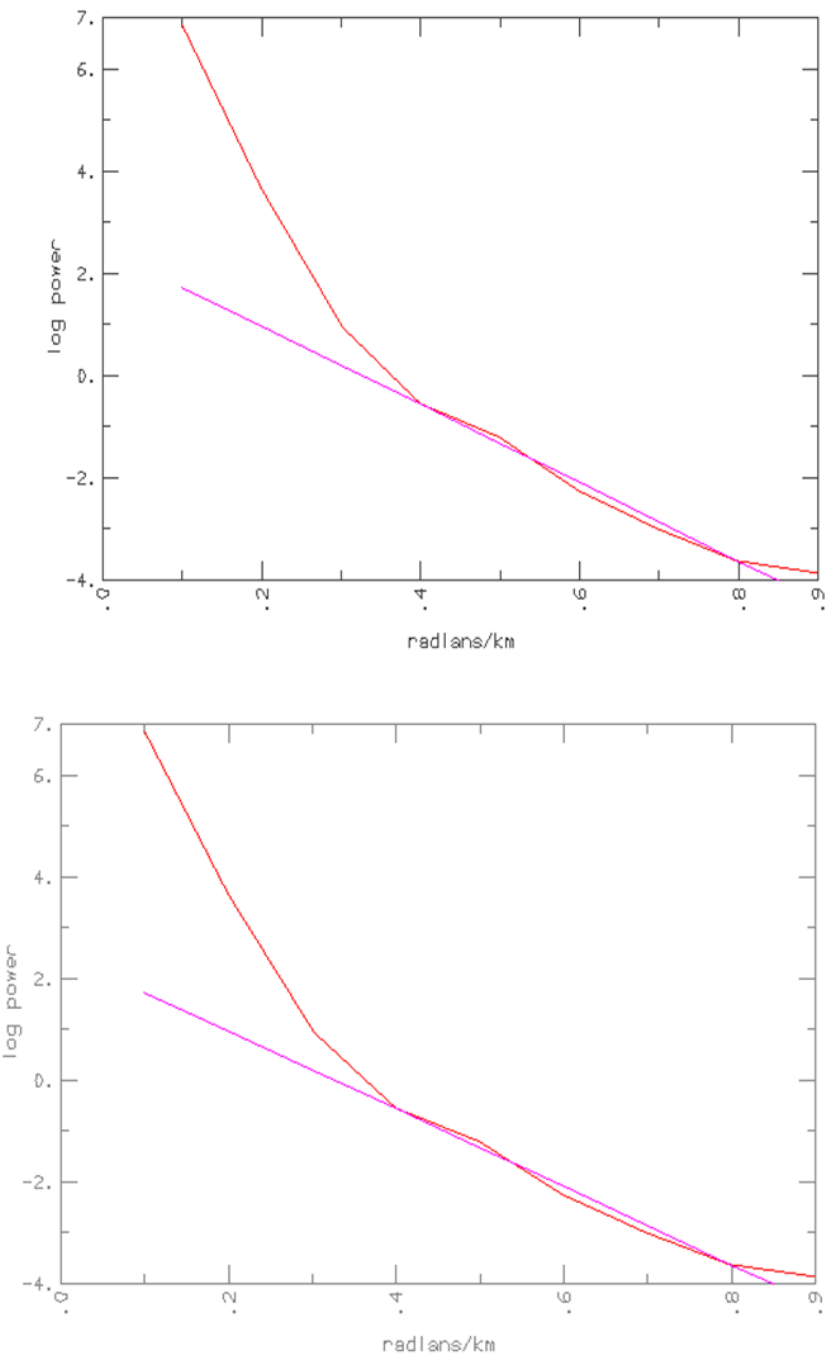

Figure 8. Energy Spectra for Blocks A, B, C, and D for the determination of basement depths

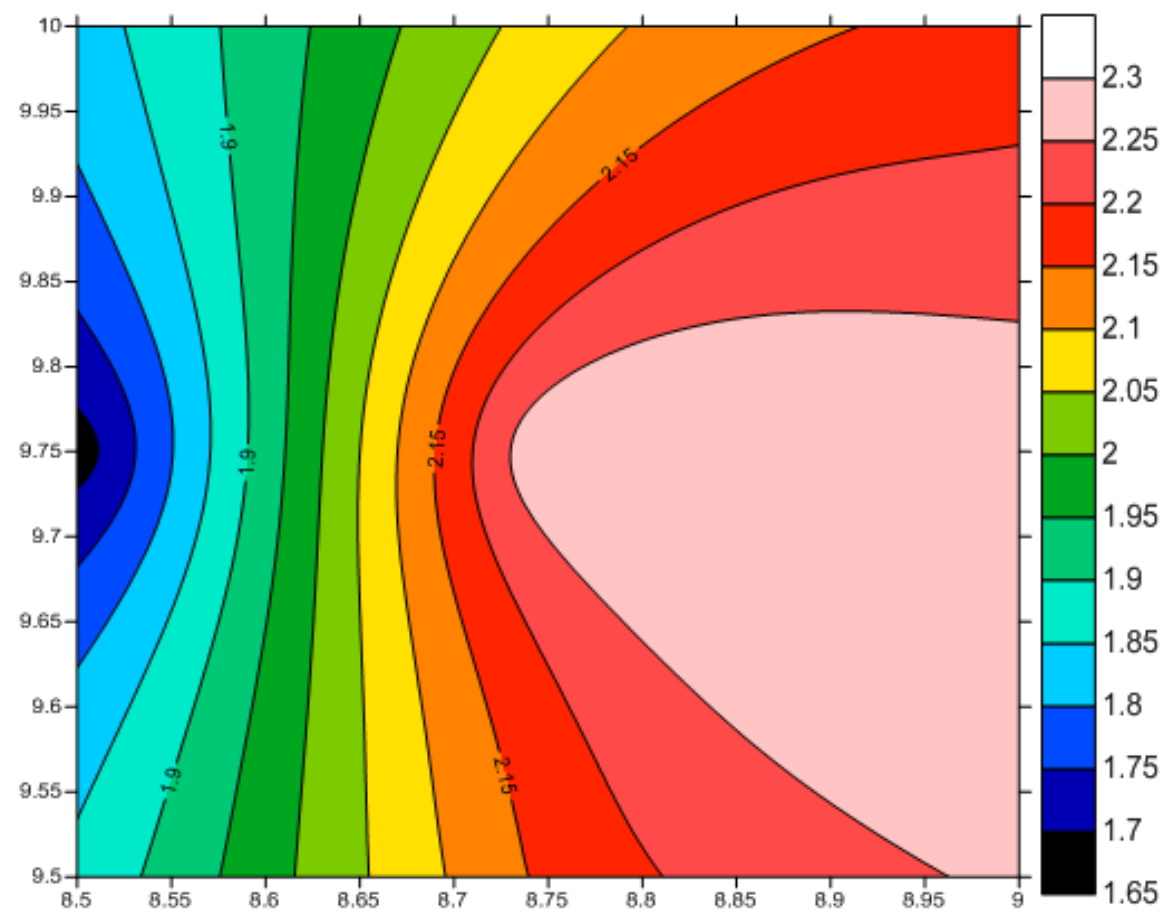

Figure 9. Depth to basement map estimated from spectral inversion contoured in metres 
3-D Standard Euler deconvolution of the aeromagnetic data of the study area using different geological scenarios based on several vintages of structural indices (structural index 0 for contacts, structural index 1 for sills and dikes, structural index 2 for horizontal cylinders and pipes, and structural index 3 for spheres), revealed standard Euler solution clusters as shown in Figure 10a - Figure 10d. For a better comparison of the obtained solutions, only solutions in the depth range between $0 \mathrm{~m}$ to $3000 \mathrm{~m}$ were used, which entailed an elimination of a few spurious solutions. The Euler solutions used for the plots were gotten under the assumption of a wide range of geologic models determined represented by contacts, dike/ sill, horizontal cylinder/pipes and spheres; thus structural indices of 0 to 3 were used. While solutions were gotten for the standard Euler deconvolution, using the different structural indices, there is however a similarity in all the solutions. The Standard Euler solutions for four geological models are presented in this model. Figure 10a is the Standard Euler solution for contacts (structural index $=0$ ). This figure revealed a depth range of 250 - 3000m with isolated cluster of solutions around Makusuwa, Jos and Vwang areas. This indicates that magnetic contacts are not a dominant geological feature of the study area. Figure $10 \mathrm{~b}$ on the other hand represents the Standard Euler
Solutions for sills/dikes. The depth estimate of this geological model in the study area ranges from $0 \mathrm{~m}$ to a little above $3000 \mathrm{~m}$. It is therefore revealed that sills/dikes are dominant geological features in the study area as the cluster of solutions all over the map. However, there is a complete absence of this geological structure around Tsofo. Similarly, for structural index 2(horizontal cylinders/pipes), the estimated depth ranges from 1000 to $3000 \mathrm{~m}$ as shown in Figure 10c. Several clusters of solutions were observed all over the map of the study area with Jos however having no noticeable cluster of solution. Horizontal cylinders/pipes are therefore observed to be dominant structural/geological feature in the study area. Finally, Figure 10d (spheres) revealed a concentration of clusters of solution at the central and southern parts. There is also a concentration of the cluster of solutions representing spheres around Tsofo area in the northern part. The depth of the interpreted cluster of solutions varies between $1000-3000 \mathrm{~m}$. Generally, the Euler deconvolution suggests a depth to the magnetic source of between $0 \mathrm{~m}$ to a little above $3000 \mathrm{~m}$. Comparing these depth estimates with the information gotten from the spectral analysis, there is a positive correlation between the results from both depth estimation methods.

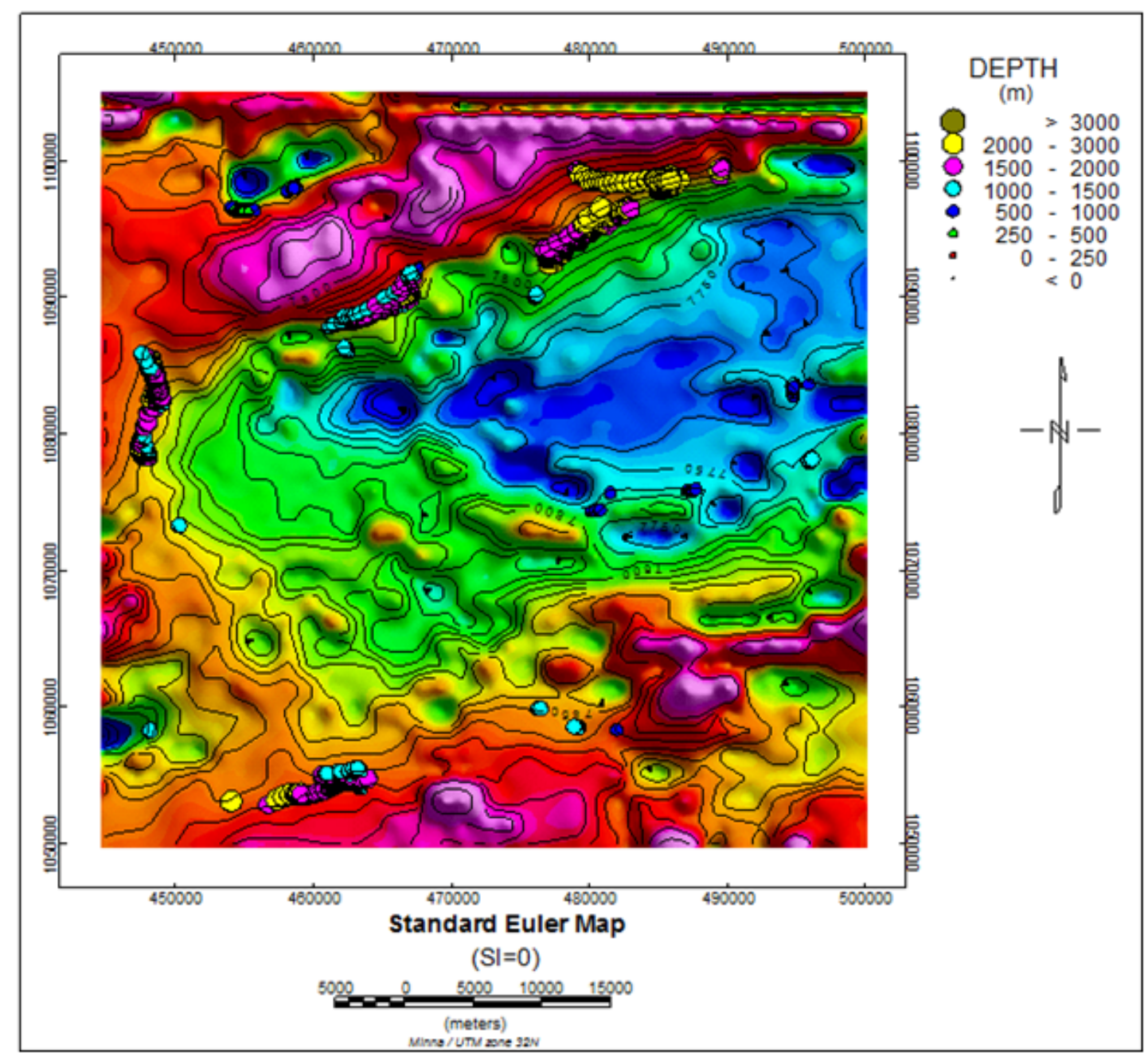

Figure 10a. Standard Euler Deconvolution Depth Solution Plot Draped on the Colour Shaded Grid of the Total Magnetic Intensity of the Study area (Structural Index $=0$ ) 


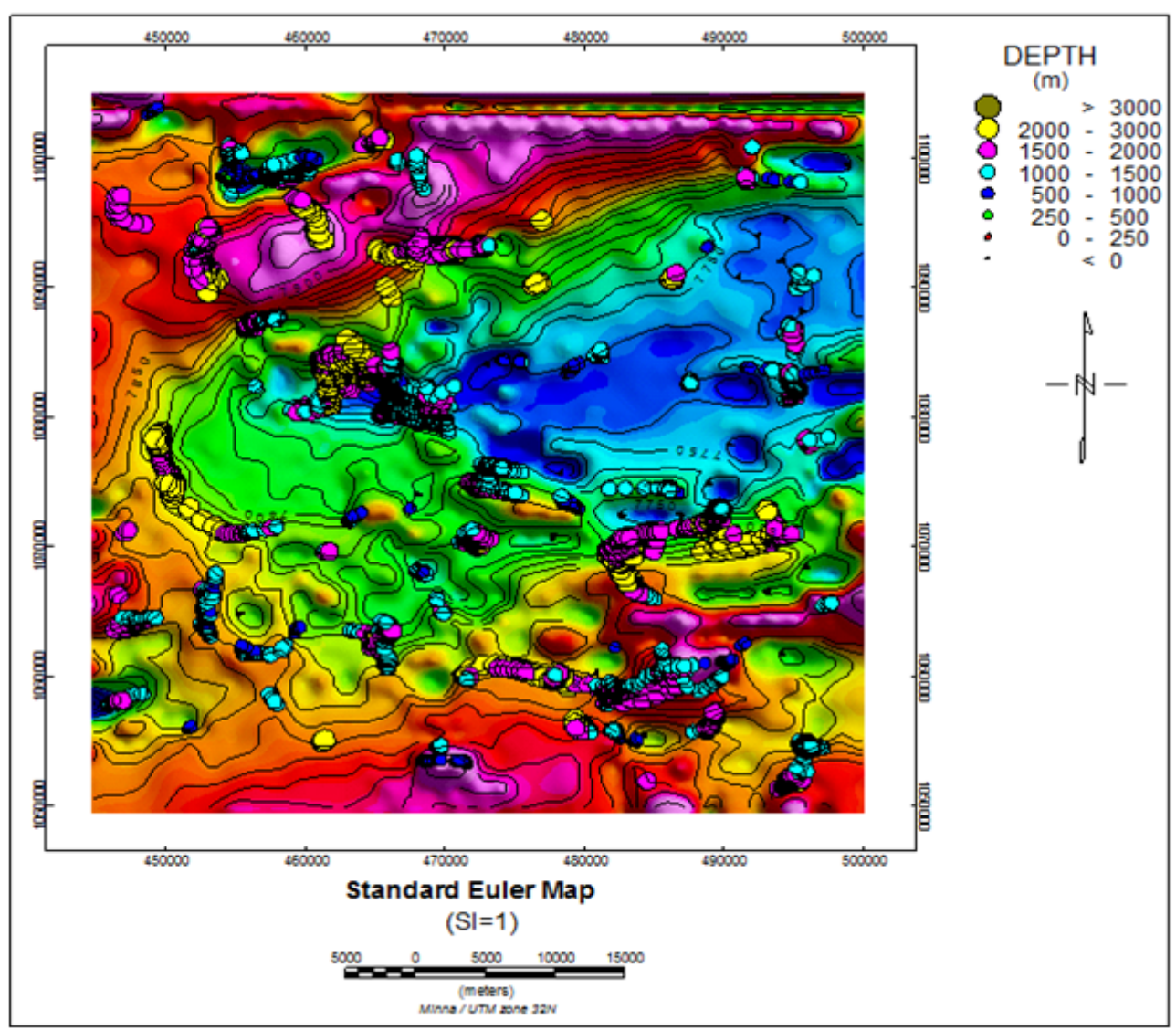

Figure 10b. Standard Euler Deconvolution Depth Solution Plot Draped on the Colour Shaded Grid of the Total Magnetic Intensity of the Study area (Structural Index=1)

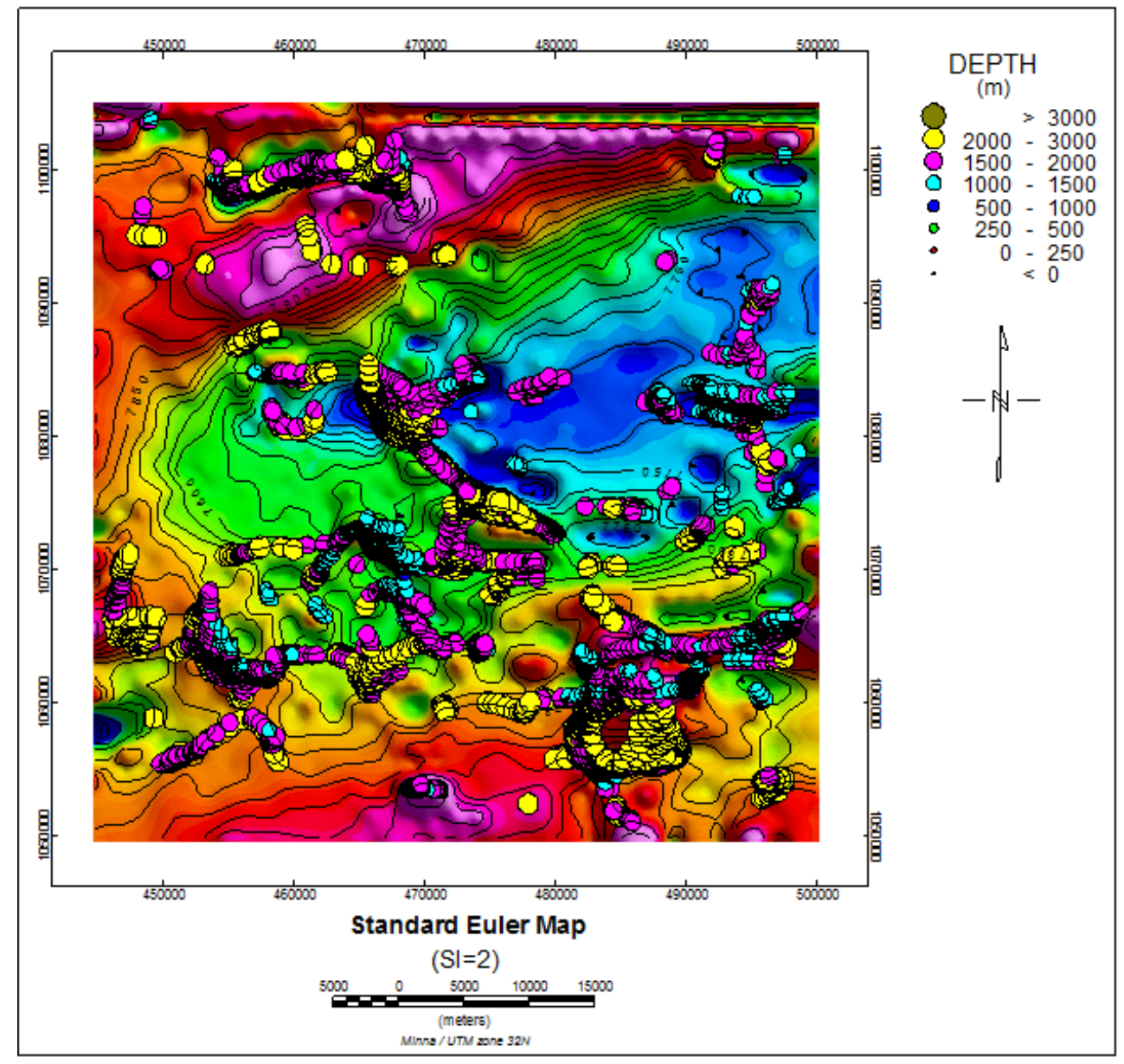

Figure 10c. Standard Euler Deconvolution Depth Solution Plot Draped on the Colour Shaded Grid of the Total Magnetic Intensity of the Study area. (Structural Index=2) 


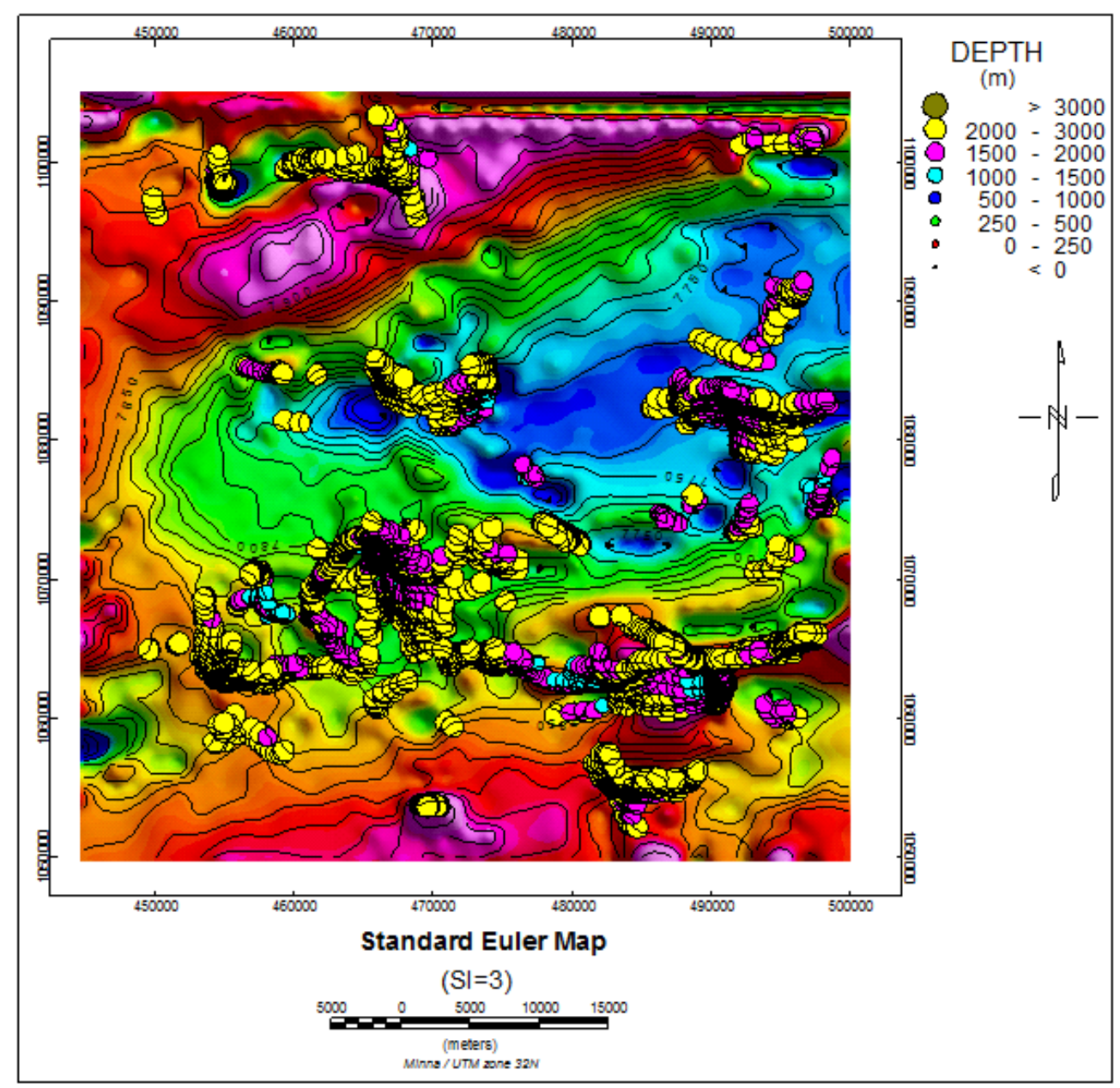

Figure 10d. Standard Euler Deconvolution Depth Solution Plot Draped on the contour map of the total map intensity field of the study area (Structural Index=3)

\section{Discussion and Conclusion}

A detailed structural interpretation and re-evaluation of the magnetic basement depth in the study area was carried out using 3-D Standard Euler deconvolution and spectral inversion techniques. The presence of intrusive bodies in some parts of the study area suggests that some parts of the area are more tectonically active than others. The extensive linear anomaly observed at Tsofo is suspected to be part of the ring faulting prevalent in the Younger Granite Complex. Structural analysis of the interpreted anomalies(intrusive bodies) using 3-D Standard Euler deconvolution with structural index values ranging from 0-3 revealed the dominant presence of three geological structural features which include spheres, horizontal pipes/cylinders and sills/ dikes. Results of the 2-D spectral analysis revealed a two layer depth source model. The spectral depths obtained in this study revealed the depth to the shallow magnetic layer to be in the range of $0.55 \mathrm{~km}$ to $0.897 \mathrm{~km}$ with an average depth of $0.711 \mathrm{~km}$, while the depth to the magnetic basement varies from $1.672 \mathrm{~km}$ to $2.3 \mathrm{~km}$ with an average depth of $1.999 \mathrm{~km}$.It can be deduced that the $D_{2}$ values obtained from the spectral depth represent the average depth to the magnetic basement in the blocks considered. The shallower magnetic anomalies are however believed to be as the result of basement rocks which intruded into the sedimentary rocks while the deeper layer may be attributed to magnetic basement surface and intrabasement discontinuities like faults. Similarly, the depth to the anomalous magnetic features from the three depth slope methods revealed depth values that range from $0.1601 \mathrm{~km}$ to $2.478 \mathrm{~km}$. Finally, magnetic basement depth estimates using 3-D Euler deconvolution revealed a magnetic basement depth range of $0.5-3.0 \mathrm{~km}$. This average depth of $1.999 \mathrm{~km}$ from this study is fairly close to that of the neighbouring Nupe Basin which has a basement depth of $3.3 \mathrm{~km}[1,21]$. Elsewhere in the Benue Trough, a sedimentary thickness of $3.3 \mathrm{~km}$ was estimated [9]. Depth to source interpretation of aeromagnetic field data provides important information on basin architecture for mapping areas where the basement is shallow enough for mineral exploration.

Economically, the area has low hydrocarbon exploration potential owing to the shallow sedimentary thickness and numerous tectonic activities that affected the study area which are seen on the aeromagnetic map as lineations (fractures, joints, faults, etc). The average sedimentary thickness of $1.999 \mathrm{~km}$ estimated from this study may be unfavorable for hydrocarbon generation and accumulation. Another reason that may have affected the hydrocarbon bearing potentials of the area are the high thermal gradients associated with igneous activities believed to have taken place in the region. However, the area is more viable for solid mineral exploitation based on the presence of linear features which may have acted as conduits for mineralization. Finally, the NE-SW trend of 
the study area suggests a relationship between the Younger Granite Complex of Jos and the Benue Trough. This trend suggests that the tectonic events that took place in the Benue trough may have extended to the Younger Granite Complex of Jos.

\section{References}

[1] Adeniyi, J.O., (1986). Polynomial Regional Surfaces and Two dimensional models in parts of Nupe Basin and Adjacent Basement Complex, Niger State, Nigeria. Nigerian Jour. of Applied Sciences. Vol. 4, pp. 25-34.

[2] Akanbi, E.S., Ugodulunwa, F.X.O. and Gyang, B.N., (2012). Mapping Potential Cassiterite Deposits of Naraguta Area, North Central, Nigeria using Geophysics and Geographic Information System (GIS). Journal of Natural Sciences Research. Vol.2, (8),

[3] Blakely, R.J., (1995). Potential theory in gravity and magnetic applications: Cambridge Univ. Press.

[4] Bowden, P, and Kinnaird, J.A. (1984). Geology and mineralization of the Nigerian anorogenic ring complexes. Geologisches Jahrb (Hannover) B56, 3-65.

[5] Buser, H. (1966). Paleostructures of Nigeria and adjacent Countries. Geotectonic Res. E. Schweizerbart Sci. Publi., Johannesstr. 3A D-70176 Stuttgart, Germany. Vol. 24.

[6] Gunn, P. J. (1997). Application of Aeromagnetic Survey to Sedimentary Basin Studies. AGSO Journal of Australian Geology and Geophysics 17, 2, 133-144.

[7] Hahn, A., Kind, E. G. and Mishra, D. C. (1976): Depth estimation of Magnetic sources by means of Fourier amplitude spectra, Geophysical. Prospecting, 24, 287-308.

[8] Kangoko, R., Ojo, S.B. and Umego, M.N., (1997). Estimation of Basement depths in the Middle Cross River basin by Spectral analysis of the Aeromagnetic field. Nig. Journ. of Phys. Vol. 9, pp.30-36.

[9] Kogbe, C.A., (1989). The Cretaceous and Paleogene Sediments of Southern Nigeria. Geology of Nigeria 2nd Edition. Rock View (Nig) Ltd, pp. 325-334.

[10] Liu, X., (2003). On the use of different methods for estimating magnetic depth: The Leading Edge, November, pp. 1090-1099.

[11] Obaje, N.G., (2009). Geology and Mineral Resources of Nigeria. Springer-Verlag Berlin Heidelberg, P. 219.
[12] Ofoegbu, C. O., and Onuoha, K. M., (1991). Analysis of magnetic data over the Abakaliki Anticlinorium of the Lower Benue Trough, Nigeria. Marine and Petr.Geol. vol. 8.

[13] Opara, A.I., (2011). Estimation of the Depth to Magnetic Basement in Part of the Dahomey Basin, Southwestern Nigeria. Australian Journal of Basic and Applied Sciences, Vol. 5(9), 335343.

[14] Reid, B., Allsop, J.M., Granser, H. Millet, A.J., and Somerton., I. W., (1990). Magnetic interpretation in three dimensions using Euler deconvolution., Geophysics. Vol. 55, No. I; P. 80-91.

[15] Salem, A., Ushijima, K., Elsirafi, A. and Mizunaga, H., (2000). Spectral analysis of aeromagnetic data for Geothermal reconnaissance of Uaseir area, Northern Red Sea, Egypt. Proceedings of World Geothermal Congress, Kyushu-Tohokie, Japan, 28: 10.

[16] Sharma, P. V. (1987). Magnetic Method Applied to Mineral Exploration; Ore Geology, Review. 2, 323-357.

[17] Samaila, C. A and Solomon, N. Y., 2011. Groundwater Potential on the Jos-Bukuru Plateau, North Central Nigeria, using lineaments from gravity measurements; Journal of Water Resource and Protection, vol. 3; pp. 628-633.

[18] Spector, A. and Grant, F.S., (1970). Statistical models for interpreting aeromagnetic data. Geophysics, Vol.35, pp. 293-302.

[19] Thompson, D. T. (1982). EULDPH: A new technique for making computer-assisted depth estimates from magnetic data, Geophysics, 47, 31-37.

[20] Turner., D. C.1989. Structure and Petrology of the Younger Granite Ring Complexes,” In: C.A Ogbe, Ed., Geology of Nigeria, Rock View International, France, 1989, pp. 175-190.

[21] Udensi, E.E. and Osazuwa, I.B., (2000). Spectral determination of depths to buried magnetic rocks under the Nupe Basin, Nigeria. Proceedings of the 23rd annual conference of the Nigerian Institute of Physics “The Millenium Conference”. pp. 170-176.

[22] Udensi, E.E. and Osazuwa, I.B., (2004). Spectral determination of depth to buried magnetic rocks under the Nupe Basin, Nigeria. Nigerian Association of Petroleum Explorationists Bulletin, Vol. 17(1), pp. 22-27.

[23] Whitehead, N. and Musselman, C. (2008). Montaj Gravity/Magnetic Interpretation: Processing, Analysis and Visualization System for 3D Inversion of Potential Field Data for Oasis montaj v6.3, Geosoft Incorporated, 85 Richmond St. W., Toronto, Ontario, M5H 2C9, Canada. 